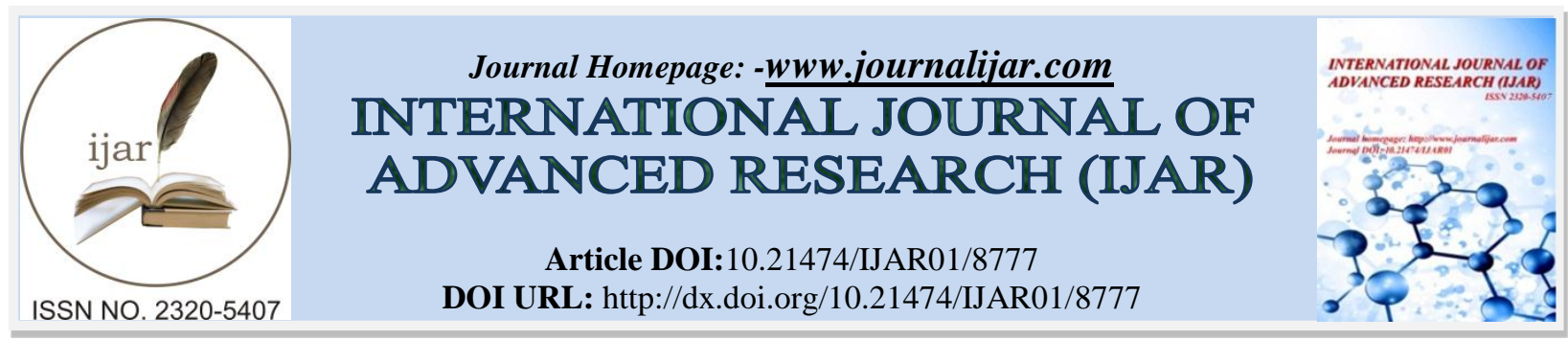

RESEARCH ARTICLE

\title{
EVALUATION OF ROOT AND CANAL MORPHOLOGY OF MAXILLARY PERMANENT PREMOLARS IN AN EGYPTIAN POPULATION BY CONE-BEAM COMPUTED TOMOGRAPHY.
}

Amr Ahmed Bayoumi ${ }^{1}$, Ahmed Mostafa Ghobashy ${ }^{2}$ and Mohamed Mokhtar Nagy ${ }^{3}$.

1. (PhD),Lecturer of Endodontics . Department of Conservative Dentistry. Faculty of Dentistry. Misr International University. Cairo. Egypt.

2. (PhD),Assoociate professor of Endodontics . Department of Conservative Dentistry. Faculty of Dentistry. Misr International University. Cairo. Egypt.

3. (PhD),Associate Professor of Endodontics . Department of Endodontics. Faculty of Dentistry. Ain Shams University. Cairo. Egypt.

\section{Manuscript Info}

\section{Manuscript History}

Received: 20 January 2019

Final Accepted: 22 February 2019

Published: March 2019

Key words:-

Behaviour, determinant, factor, health, seeking.

\section{Abstract}

Introduction: The purpose of this study was to evaluate the number of roots and canal morphology of maxillary permanent premolars in Egyptian population.

Methods: seven hundred and eighteen cases were included in this study. Digitized images from cone-beam computed tomography were assessed by 2 endodontists. Number of roots and canals configuration according to Vertucci were tabulated.

Results:Most of maxillary first premolars showed two-root configuration, while most of maxillary second premolars showed single root configuration. For maxillary first premolar ,The most common Vertucci classifications for the single root were type II (62.6\%) and III (12.6\%). While the most common Vertucci classifications for single rooted maxillary second premolar were I (44\%) followed by II (29.8\%) and III (17.9\%)

Conclusions: Under the condition of this study, the root canal configurations of an Egyptian population showed that most maxillary first premolars were two-rooted with 2 root canals, whereas maxillary second premolars tended to be single-rooted with one or two root canals more or less equally distributed. In vivo CBCT imaging is a clinically effective tool for providing comprehensive information about the root canal morphology of various teeth.

Copy Right, IJAR, 2019,. All rights reserved.

\section{Introduction:-}

Knowledge of the complex three-dimensional root canal anatomy is considered crucial for the success of root canal therapy $(1,2)$.

Lack of knowledge and/or technical skill may result in a failure to identify all root canals and hence inadequate instrumentation leading to treatment failure.

Corresponding Author:-Amr Ahmed Bayoumi.

Address:-(PhD),Lecturer of Endodontics . Department of Conservative Dentistry. Faculty of

Dentistry. Misr International University, Cairo. Egypt. 
In vitro studying of the complexity of internal anatomic variations of roots and root canals has been documented using different methods including canal staining and tooth clearing techniques (3), contrast medium-enhanced radiography (4) and micro computed tomography (5). However, these techniques are limited to extracted teeth restricting the application of these techniques in routine clinical practice.

In clinical point of view, Identifying the root canal morphology is achieved using either conventional radiography (6) or cone-beam computed tomography (CBCT) (7-10). Conventional radiography yield only two dimensional images resulting in the distortion and structures superimposition. With the introduction of cone beam computed tomography (CBCT), 3D root canal anatomy is now visible. with unquestionably lower radiation doses and better image resolution than conventional computed tomography rendering it applicable for clinical use(11).

The variation of internal root canal anatomy is genetically determined justifying the importance of ethnic variations during clinical practice.

The aim of this study was to identify the root and canal morphology of the maxillary first and second premolars in an Egyptian population using Cone Beam Computed Tomography.

\section{Materials and Methods:-}

Based on data from a previous studies(12,13), power calculation was performed using G*Power 3.1 software(14) (Heinrich Heine University, Dusseldorf, Germany). The calculation indicated that the recommended sample size should be of a minimum of 648. Digital CBCT images of the maxillary first and second premolars were collected from patients who had undergone CBCT scanning for diagnosis purposes at Misr International University from January 2017 to September 2018. The CBCT images of 718 patients were selected according to the following inclusion criteria:

1. Age between 16 and 75 years

2. Presence of the maxillary first and/or second premolar.

3. Maxillary premolars with fully matured apices and without apical periodontitis

4. No root canal fillings, posts, or full crown restorations

The CBCT images were obtained using a Cranex 3D (Soredex, Tuusula, Finland) with the following parameters: 80 $\mathrm{kVp}, 9.0 \mathrm{~mA}$, and $133 \mu \mathrm{m}$ voxel size. Serial axial, coronal, and sagittal CBCT images were acquired by an qualified radiologist. All the images were assessed independently by 2 endodontists, and any disagreement between them was discussed until a consensus was reached.

The number and configuration of the roots, the number of root canals, the canal configurations according to Vertucci's classification (3).

Demographic data including the sex, tooth position (right or left side), and age were recorded. Statistical analysis was performed using SPSS (Version 20.0; SPSS Inc, Chicago, IL) software.

\section{Results:-}

A total of 671 maxillary first premolars and 678 maxillary second premolars in 718 patients comprising $51.3 \%$ females and $48.7 \%$ men were assessed (table 1 ).

\section{Number and Morphology of Roots}

Regarding the maxillary first premolars (table 2), two-root configuration was recorded in $62.6 \%$ of the patients, One-root configuration was recorded in $36.7 \%$ whereas three-root configuration was recorded in $0.7 \%$.

While for the maxillary second premolars (table 3), the most common configuration was one-root (93\% of the cases) followed by two-root configuration $(7 \%)$

\section{Number and Configuration of Root Canals}

The number and configuration of root canals are shown in Table 4-5

The canal morphology was analyzed using Vertucci's classification for each root. Example is shown in Figure 1 
Table 1:-Prevalence of Roots According to Gender:

\begin{tabular}{|l|l|l|l|l|l|}
\hline \multirow{2}{*}{$\begin{array}{l}\text { Maxillary first } \\
\text { premolar }\end{array}$} & Male & One-root & Two-root & Three-root & Total \\
\cline { 2 - 6 } & Female & $124(37.9 \%)$ & $201(61.5 \%)$ & $2(0.6 \%)$ & 327 \\
\cline { 2 - 6 } & Total & $22(35.5 \%)$ & $219(63.6 \%)$ & $3(0.9 \%)$ & 344 \\
\hline \multirow{2}{*}{$\begin{array}{l}\text { Maxillary } \\
\text { second premolar }\end{array}$} & Male & $307(92.7 \%)$ & $24(7.3 \%)$ & $0(0 \%)$ & 671 \\
\cline { 2 - 7 } & Female & $323(93.1 \%)$ & $24(6.9 \%)$ & $0(0 \%)$ & 331 \\
\cline { 2 - 6 } & Total & $630(93 \%)$ & $48(7 \%)$ & $0(0 \%)$ & 678 \\
\hline
\end{tabular}

Table 2:-Root canal configuration in the maxillary first premolars:

\begin{tabular}{|c|c|c|c|c|c|c|c|}
\hline $\begin{array}{l}\text { Molar } \\
\text { configuration }\end{array}$ & root & $\begin{array}{l}\text { Type I } \\
\text { (1) }\end{array}$ & $\begin{array}{l}\text { Type II } \\
(2-1)\end{array}$ & $\begin{array}{l}\text { Type III } \\
(1-2-1)\end{array}$ & $\begin{array}{l}\text { Type IV } \\
(2-2)\end{array}$ & $\begin{array}{l}\text { Type V } \\
(1-2)\end{array}$ & $\begin{array}{l}\text { Type VI } \\
(2-1-2)\end{array}$ \\
\hline \multirow[t]{4}{*}{ Two-root } & \multirow[t]{2}{*}{ B } & 407 & 7 & 0 & 6 & 0 & 0 \\
\hline & & $96.9 \%$ & $1.7 \%$ & $0.0 \%$ & $1.4 \%$ & $0.0 \%$ & $0.0 \%$ \\
\hline & \multirow[t]{2}{*}{$\mathrm{P}$} & 420 & 0 & 0 & 0 & 0 & 0 \\
\hline & & $100 \%$ & $0.0 \%$ & $0.0 \%$ & $0.0 \%$ & $0.0 \%$ & $0.0 \%$ \\
\hline \multirow[t]{2}{*}{ One-root } & & 6 & 154 & 31 & 18 & 37 & 0 \\
\hline & & $2.4 \%$ & $62.6 \%$ & $12.6 \%$ & $7.3 \%$ & $15.0 \%$ & $0.0 \%$ \\
\hline \multirow[t]{6}{*}{ Three-root } & \multirow[t]{2}{*}{ MB } & 5 & 0 & 0 & 0 & 0 & 0 \\
\hline & & $100 \%$ & $0.0 \%$ & $0.0 \%$ & $0.0 \%$ & $0.0 \%$ & $0.0 \%$ \\
\hline & \multirow[t]{2}{*}{ DB } & 5 & 0 & 0 & 0 & 0 & 0 \\
\hline & & $100 \%$ & $0.0 \%$ & $0.0 \%$ & $0.0 \%$ & $0.0 \%$ & $0.0 \%$ \\
\hline & \multirow[t]{2}{*}{$\mathrm{P}$} & 5 & 0 & 0 & 0 & 0 & 0 \\
\hline & & $100 \%$ & $0.0 \%$ & $0.0 \%$ & $0.0 \%$ & $0.0 \%$ & $0.0 \%$ \\
\hline
\end{tabular}

Table 3:-Root canal configuration in the maxillary second premolars:

\begin{tabular}{|c|c|c|c|c|c|c|c|c|}
\hline $\begin{array}{l}\text { Molar } \\
\text { configuration }\end{array}$ & root & $\begin{array}{l}\text { Type I } \\
\text { (1) }\end{array}$ & $\begin{array}{l}\text { Type II } \\
(2-1)\end{array}$ & $\begin{array}{l}\text { Type III } \\
(1-2-1)\end{array}$ & $\begin{array}{l}\text { Type IV } \\
(2-2)\end{array}$ & $\begin{array}{l}\text { Type V } \\
(1-2)\end{array}$ & $\begin{array}{l}\text { Type VI } \\
(2-1-2)\end{array}$ & $\begin{array}{l}\text { Type } \\
\text { VII }\end{array}$ \\
\hline \multirow[t]{2}{*}{ One-root } & & 277 & 188 & 113 & 12 & 34 & 0 & 6 \\
\hline & & $44.0 \%$ & $29.8 \%$ & $17.9 \%$ & $1.9 \%$ & $5.4 \%$ & $0.0 \%$ & $1.0 \%$ \\
\hline \multirow[t]{4}{*}{ Two-root } & \multirow[t]{2}{*}{ B } & 41 & 0 & 0 & 0 & 7 & 0 & 0 \\
\hline & & $85.4 \%$ & $0.0 \%$ & $0.0 \%$ & $0.0 \%$ & $14.6 \%$ & $0.0 \%$ & $0.0 \%$ \\
\hline & \multirow[t]{2}{*}{$\mathrm{P}$} & 48 & 0 & 0 & 0 & 0 & 0 & 0 \\
\hline & & $100 \%$ & $0.0 \%$ & $0.0 \%$ & $0.0 \%$ & $0.0 \%$ & $0.0 \%$ & $0.0 \%$ \\
\hline
\end{tabular}

Table 4:-Root Number of Maxillary First Premolars in Various Studies:

\begin{tabular}{|l|l|l|l|l|l|l|}
\hline Author & year & Sample size & Population & $\begin{array}{l}\text { One-root } \\
\text { percentage }\end{array}$ & $\begin{array}{l}\text { Two-root } \\
\text { percentage }\end{array}$ & $\begin{array}{l}\text { Three-root } \\
\text { percentage }\end{array}$ \\
\hline $\begin{array}{l}\text { Pineda and } \\
\text { Kuttler }\end{array}$ & 1972 & 259 & USA & 43 & 54.6 & 2.4 \\
\hline $\begin{array}{l}\text { Carms and } \\
\text { Skidmore }\end{array}$ & 1973 & 100 & USA & 22 & 72 & 6 \\
\hline Walker & 1987 & 100 & Chinese & 60 & 40 & 0 \\
\hline Pecora et al & 1992 & 240 & Brazilian & 55.8 & 41.7 & 2.5 \\
\hline Loh & 1998 & 957 & Singaporean & 49.4 & 50.6 & 0 \\
\hline Kartal et al & 1998 & 300 & Turkish & 37.3 & 61.3 & 1.3 \\
\hline Chaparro et al & 1999 & 150 & Spanish & 40 & 56.7 & 3.3 \\
\hline Lipski et al & 2003 & 142 & Polish & 15.5 & 75.4 & 9.2 \\
\hline Atieh & 2008 & 246 & Saudi & 17.9 & 80.9 & 1.2 \\
\hline Awawdeh & 2008 & 600 & Jordanian & 30.8 & 68.4 & 0.8 \\
\hline Neelakantan & 2011 & 350 & Indian & 11.7 & 86 & 2.3 \\
\hline Ozcan et al & 2012 & 653 & Turkish & 45.2 & 55.7 & 1.1 \\
\hline
\end{tabular}




\begin{tabular}{|l|l|l|l|l|l|l|}
\hline Tian et al & 2012 & 300 & Chinese & 66 & 33 & 1 \\
\hline Abella et al & 2015 & 430 & Spanish & 46 & 51.4 & 2.6 \\
\hline Burklein et al & 2017 & 644 & German & 36.4 & 62.4 & 1.2 \\
\hline Present study & 2018 & 671 & Egyptian & 36.7 & 62.6 & 0.7 \\
\hline
\end{tabular}

Table 5:-Root Number of Maxillary Second Premolars in Various Studies:

\begin{tabular}{|l|l|l|l|l|l|l|}
\hline Author & year & Sample size & Population & $\begin{array}{l}\text { One-root } \\
\text { percentage }\end{array}$ & $\begin{array}{l}\text { Two-root } \\
\text { percentage }\end{array}$ & $\begin{array}{l}\text { Three-root } \\
\text { percentage }\end{array}$ \\
\hline Pecora et al & 1992 & 435 & Brazilian & 90.3 & 9.7 & 0 \\
\hline Kartal et al & 1998 & 300 & Turkish & 69.6 & 29.7 & 0.7 \\
\hline Yang et al & 2014 & 392 & Chinese & 86.5 & 13.5 & 0 \\
\hline Abella et al & 2015 & 374 & Spanish & 82.9 & 15.5 & 1.6 \\
\hline Burklein et al & 2017 & 512 & German & 82.6 & 17 & 0.4 \\
\hline Present study & 2018 & 678 & Egyptian & 93 & 7 & 0 \\
\hline
\end{tabular}

\section{Discussion:-}

Due to high rates of variation in maxillary molars, thorough understanding of root canal morphology is essential for successful root canal therapy. The aim of this study was to investigate the root and root canal morphology of maxillary first and second premolars in an Egyptian population using CBCT imaging.

The present study included CBCT scans of 718 patients resulting in a satisfactory number of teeth for comparison with results obtained from other studies in other populations $(6,12,13,15-27)$.

Many in-vitro methods have been advocated for investigating the root canal morphology including, tooth-clearing technique with or without the use of microscope (28-31) and Micro-computed tomography (32-36). Unfortunately, all in vitro techniques are only applicable to extracted teeth and hence limiting the sample size. CBCT is considered a dependable yet non-destructive method for evaluation of root canal morphology providing high resolution images with definite lower radiation dose and lower cost compared with micro computed tomography.

Domark et al (5) found that there was no significant difference between CBCT and micro computed tomography in canals identification for maxillary molars. Blattner et al (37) compared CBCT results with tooth sectioning results and concluded that there was no difference regarding the accuracy of CBCT.

In our study, A total of 718 CBCT scans were evaluated for bilateral maxillary premolars. 671 maxillary first premolars and 678 maxillary second premolars were included in the study.

Among the evaluated maxillary first premolars, two-root configuration was the most predominant configuration $(62.6 \%)$. These findings were very similar to many previous studies conducted in other populations $(12,16,17,25)$ as shown in table 4 . However other studies showed that the frequency of single rooted maxillary premolars was higher than double rooted(19,22,23). These differences in root canal morphology highlight the influence of ethnic origins on the teeth morphology. The three-root configuration appeared to be rare in most of the studies $(6,12,13,15-$ $19,23,25,26)$.

For the three and two-root configurations, Type I is by far the most common configuration (table 2). However for single-rooted maxillary first premolars, type II constitute $62.6 \%$ of the examined scans which is considerably higher than previous studies $(3,6,12,38)$.

Regarding the maxillary second premolar, one-root configuration recorded 93\% of the examined scans (table5) which is slightly higher than previous records $(12,13,20,23,25)$. However type I and II were prevailing (table 3 ). This shows that maxillary second premolars have two canals in more than half of the cases regardless of the root configuration. This was in agreement with most of the previous studies(12,13,20,23,25).

Overall root morphology is not affected by gender and side which was in agreement with previous studies $(7,9)$. These findings were contradicting with another two studies $(12,39)$ who stated that male patients had significantly more roots and root canals compared with female patients 
Under the condition of this retrospective study, the root canal configurations of an Egyptian population showed that most maxillary first premolars were two-rooted with 2 root canals, whereas maxillary second premolars tended to be single-rooted with one or two root canals more or less equally distributed. In vivo CBCT imaging is a clinically effective tool for providing comprehensive information about the root canal morphology of various teeth which in turns might improve the outcome of endodontic treatment.

\section{Acknowledgement:-}

"The authors deny any conflicts of interest"

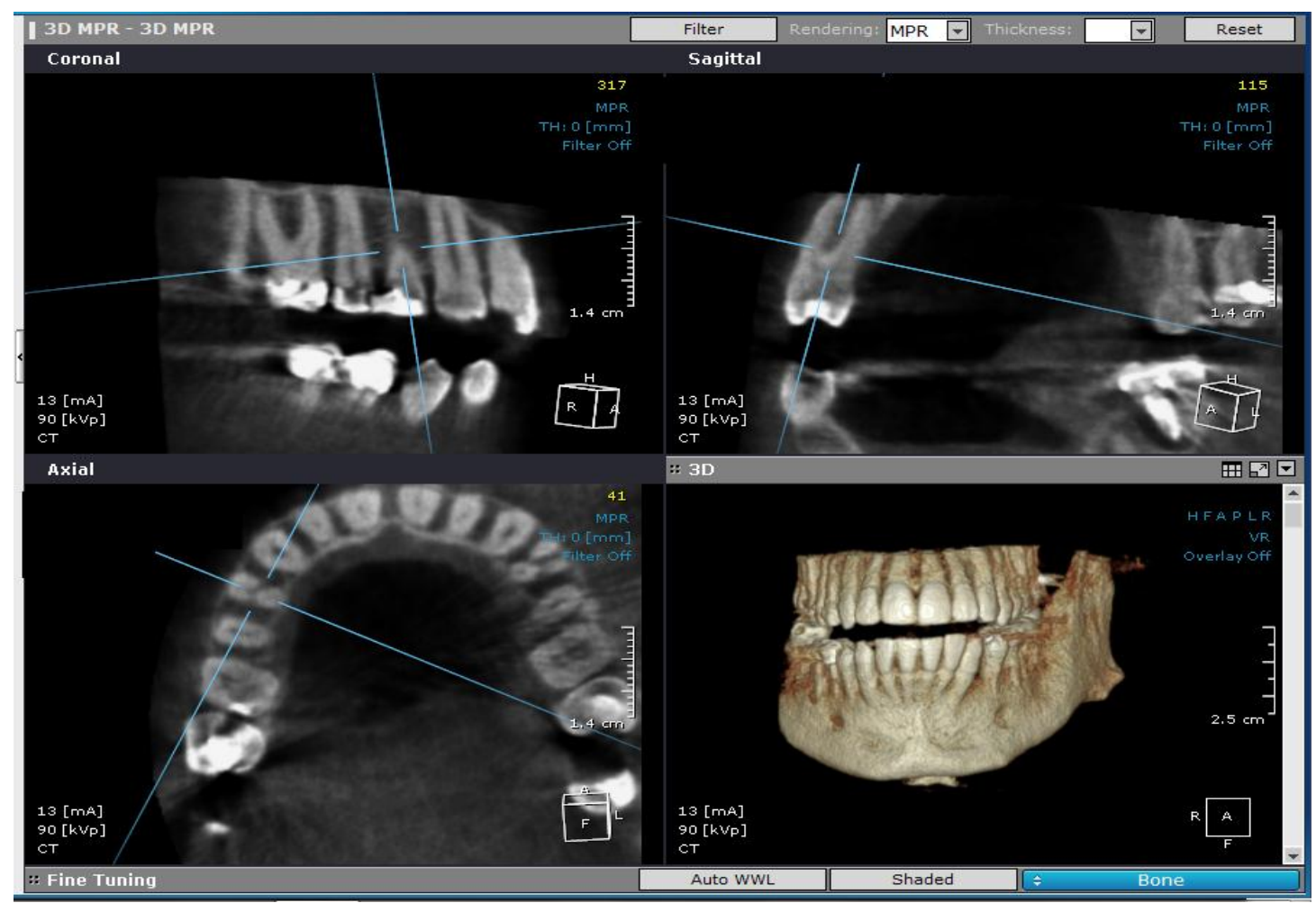

Figure 1:-Axial and sagittal section in a three-rooted maxillary first premolar.

\section{References:-}

1. Weine FS, Healey HJ, Gerstein H, Evanson L. Canal configuration in the mesiobuccal root of the maxillary first molar and its endodontic significance. Oral Surgery, Oral Med Oral Pathol. 1969;28(3):419-25.

2. Sert S, Bayirli GS. Evaluation of the root canal configurations of the mandibular and maxillary permanent teeth by gender in the Turkish population. J Endod. 2004;30(6):391-8.

3. Vertucci FJ. Root canal anatomy of the human permanent teeth. Oral Surgery, Oral Med Oral Pathol. 1984;58(5):589-99.

4. Fan B, Gao Y, Fan W, Gutmann JL. Identification of a C-shaped Canal System in Mandibular Second MolarsPart II: The Effect of Bone Image Superimposition and Intraradicular Contrast Medium on Radiograph Interpretation. J Endod. 2008;34(2):160-5.

5. Domark JD, Hatton JF, Benison RP, Hildebolt CF. An ex vivo comparison of digital radiography and conebeam and micro computed tomography in the detection of the number of canals in the mesiobuccal roots of maxillary molars. J Endod. 2013;39(7):901-5.

Pineda F, Kuttler Y. Mesiodistal and buccolingual roentgenographic investigation of 7,275 root canals. Oral Surgery, Oral Med Oral Pathol. 1972;33(1):101-10.

6. Zheng Q, Wang Y, Zhou X, Wang Q, Zheng G, Huang D. A Cone-Beam Computed Tomography Study of Maxillary First Permanent Molar Root and Canal Morphology in a Chinese Population. J Endod. 2010;36(9):1480-4.

7. Amalorpavanathan J. Transplantation of Human Organs Act 1994--some observations. Natl Med J India. 2000;13(4):220-1. 
8. Kim Y, Lee S-J. morphology of maxillary first and second molars analyzed by CBCT in a korean population: variations in the number of roots and canals and the incidence of fusion. Joe. 2012;38(8):1063-8.

9. Rouhani A, Bagherpour A, Akbari M, Azizi M, Nejat A, Naghavi N. Cone-beam computed tomography evaluation of maxillary first and second molars in Iranian population: A morphological study. Iran Endod J. 2014;9(3):190-4.

10. Ludlow JB, Davies-Ludlow LE, Brooks SL, Howerton WB. Dosimetry of 3 CBCT devices for oral and maxillofacial radiology: CB Mercuray, NewTom 3G and i-CAT. Dentomaxillofacial Radiol. 2006;35(4):21926.

11. Bürklein S, Heck R, Schäfer E. Evaluation of the Root Canal Anatomy of Maxillary and Mandibular Premolars in a Selected German Population Using Cone-beam Computed Tomographic Data. J Endod. 2017;43(9):144852.

12. Abella F, Teixidó LM, Patel S, Sosa F, Duran-Sindreu F, Roig M. Cone-beam Computed Tomography Analysis of the Root Canal Morphology of Maxillary First and Second Premolars in a Spanish Population. J Endod. 2015;41(8):1241-7.

13. Faul F, Erdfelder E, Lang AG, Buchner A. G*Power 3: A flexible statistical power analysis program for the social, behavioral, and biomedical sciences. In: Behavior Research Methods. 2007. p. 175-91.

14. Özcan E, Çolak H, Hamidi MM. Root and canal morphology of maxillary first premolars in a Turkish population. J Dent Sci. 2012;7(4):390-4.

15. Awawdeh L, Abdullah H, Al-Qudah A. Root Form and Canal Morphology of Jordanian Maxillary First Premolars. J Endod. 2008;34(8):956-61.

16. Neelakantan P, Subbarao C, Ahuja R, Subbarao CV. Root and canal morphology of Indian maxillary premolars by a modified root canal staining technique. Odontology. 2011;99(1):18-21.

17. Bulut DG, Kose E, Ozcan G, Sekerci AE, Canger EM, Sisman Y. Evaluation of root morphology and root canal configuration of premolars in the Turkish individuals using cone beam computed tomography. Eur J Dent. 2015;9(4):551-7.

18. Tian YY, Guo B, Zhang R, Yu X, Wang H, Hu T, et al. Root and canal morphology of maxillary first premolars in a Chinese subpopulation evaluated using cone-beam computed tomography. Int Endod J. 2012;45(11):9961003.

19. Yang L, Chen X, Tian C, Han T, Wang Y. Use of Cone-beam Computed Tomography to Evaluate Root Canal Morphology and Locate Root Canal Orifices of Maxillary Second Premolars in a Chinese Subpopulation. J Endod. 2014;40(5):630-4.

20. Carns EJ, Skidmore AE. Configurations and deviations of root canals of maxillary first premolars. Oral Surgery, Oral Med Oral Pathol. 1973;36(6):880-6.

21. Mauger MJ, Schindler WG, Walker WA. An evaluation of canal morphology at different levels of root resection in mandibular incisors. J Endod. 1998;24(9):607-9.

22. Pécora JD, Saquy PC, Sousa Neto MD, Woelfel JB. Root form and canal anatomy of maxillary first premolars. Braz Dent J. 1992;2(2):87-94.

23. Loh HS. Root morphology of the maxillary first premolar in Singaporeans. Aust Dent J. 1998;43(6):399-402.

24. Kartal N. Root canal morphology of maxillary premolars. J Endod. 1998;24(6):417-9.

25. Chaparro AJ, Segura JJ, Guerrero E, Jiménez-Rubio A, Murillo C, Feito JJ. Number of roots and canals in maxillary first premolars: Study of an Andalusian population. Dent Traumatol. 1999;15(2):65-7.

26. Lipski M, Woźniak K, Lagocka R TM. Root and canal morphology of the first human maxillary premolar. Vol. 12, Durham Anthropol J. 2005. p. (2-3).

27. Chen G, Yao H, Tong C. Investigation of the root canal configuration of mandibular first molars in a Taiwan Chinese population. Int Endod J. 2009;42(11):1044-9.

28. Al Shalabi RM, Omer OE, Glennon J, Jennings M, Claffey NM. Root canal anatomy of maxillary first and second permanent molars. Vol. 33, International endodontic journal. 2000. p. 405-14.

29. Ibarrola JL, Knowles KI, Ludlow MO, McKinley IB. Factors affecting the negotiability of second mesiobuccal canals in maxillary molars. J Endod. 1997;23(4):236-8.

30. Stropko JJ. Canal morphology of maxillary molars: clinical observations of canal configurations. J Endod. 1999;25(6):446-50.

31. Briseño-Marroquín B, Paqué F, Maier K, Willershausen B, Wolf TG. Root Canal Morphology and Configuration of 179 Maxillary First Molars by Means of Micro-computed Tomography: An Ex Vivo Study. J Endod. 2015;41(12):2008-13. 
32. Park JW, Lee JK, Ha BH, Choi JH, Perinpanayagam H. Three-dimensional analysis of maxillary first molar mesiobuccal root canal configuration and curvature using micro-computed tomography. Oral Surgery, Oral Med Oral Pathol Oral Radiol Endodontology. 2009;108(3):437-42.

33. Somma F, Leoni D, Plotino G, Grande NM, Plasschaert A. Root canal morphology of the mesiobuccal root of maxillary first molars: A micro-computed tomographic analysis. Int Endod J. 2009;42(2):165-74.

34. Baratto Filho F, Zaitter S, Haragushiku GA, de Campos EA, Abuabara A, Correr GM. Analysis of the Internal Anatomy of Maxillary First Molars by Using Different Methods. J Endod. 2009;35(3):337-42.

35. Cleghorn BM, Christie WH, Dong CCS. Root and Root Canal Morphology of the Human Permanent Maxillary First Molar: A Literature Review. J Endod. 2006;32(9):813-21.

36. Blattner TC, George N, Lee CC, Kumar V, Yelton CDJ. Efficacy of Cone-Beam Computed Tomography as a Modality to Accurately Identify the Presence of Second Mesiobuccal Canals in Maxillary First and Second Molars: A Pilot Study. J Endod. 2010;36(5):867-70.

37. Al-Qudah AA, Awawdeh LA. Root and canal morphology of mandibular first and second molar teeth in a jordanian population. Int Endod J. 2009;42(9):775-84.

38. E Ok, Altunsoy M, Nur B, Aglarci O, Çolak M, Güngör E. A cone-beam computed tomography study of root canal morphology of maxillary and mandibular premolars in a Turkish population. Acta Odontol Scand. 2014;72(8):701-6. 